\title{
The Effect of Animal-assisted Play Therapy (AAT) on Improving the Life Quality of Parents having Children with ADHD (Attention Deficit Hyperactivity Disorder in children) Treated with Methylphenidate
}

Nazila Motarabesoun ${ }^{1}$, Seyed Mahmoud Tabatabaei ${ }^{2 *}$

1. General Psychology graduate student, Department of Psychology,East Azarbaijan Science and Research Branch, Islamic Azad University, Tabriz, Iran

2. Department of Physiology, Tabriz Branch, Islamic Azad University, Tabriz, Iran

\begin{abstract}
Background and purpose: ADHD (Attention Deficit Hyperactivity Disorder in children) is considered to be one of the most widespread neuro-behavioral disorders in children, which is typically characterized by problems such as poor educational performance, communication difficulties and other social inconsistencies. Timely identification and treatment of this disorder can result in significant improvement in their individual and social performances and it can reduce the symptoms of this disorder. Nowadays, play therapy is regarded as one of the recent treatments. One type of play therapy is referred to as animal-assisted play therapy. Methodology: This study was based on a single case study in which two children with ADHD were studied. Before the treatment intervention, the life quality questionnaire (SF-36) was conducted on three consecutive days as the baseline. Then, based on the designed operational procedure, the stages of treatment intervention were carried out with a domestic animal (rabbit) within six 45-minute sessions. At the end of the two treatment sessions and during the whole intervention period, the dependent variable, the effect size and improvement rate were measured. Results: the results of the study indicated that the experimented animal-assisted play therapy was statistically significant for both children $(P<0.05)$. However, the rate of improvement in clinical terms was not meaningfully significant. Conclusion: with respect to the obtained significant differences in eye diagrams and the calculated physical and mental health indexes and the statistical significance of the effect size, it can be concluded that animal-assisted play therapy can contribute to the relative improvement of the life quality of these children's parents.
\end{abstract}

Keywords: ADHD (Attention Deficit Hyperactivity Disorder in children); animal-assisted play therapy; life quality of ADHD children's parents;

\section{Corresponding author:}

Seyed Mahmoud Tabatabaei

Ph.D. in Neuroscience, Department of Physiology, Tabriz Branch, Islamic Azad University, Tabriz, Iran

Email: smt1351@yahoo.com,smt@iaut.ac.ir

Receive date: 2016-05-25| Accept date: 2016-06-29| Publish date: 2016-07-28

DOI: 10.7575/aiac.abcmed.16.04.03.04 


\section{Introduction}

One of the most prevalent disorders which is of high importance in childhood and has recently attracted psychiatrists' and psychologists' attention is known as ADHD (Attention Deficit Hyperactivity Disorder in children). Beginning around age 2 to 4 years, ADHD is deemed to be a highly common neurobehavioral disorder in the childhood period. Approximately, $3 \%$ to $5 \%$ of children are affected by this disorder (Shoushtari et al., 2011). The existing etiological models about ADHD highlight the significance of interaction among the following factors: genetic factors, biological factors, environmental factors, sociopsychological factors, psychological factors, neuro-chemical factors and factor related to nutrition. For examining this disorder, some of the symptoms should emerge before age seven. However, it should be noted that, based on the DSMV classification of the emergence symptoms, the related symptoms can continue until age 12 (American Psychiatric Association, 2013). The children having this disorder create difficult conditions for themselves and their parents. This disorder can occur alone or along with some other disorders. The appearance of this disorder can determine the need for a particular treatment program for the affected child. Indeed, ADHD can be identified based on a basic pattern of attention deficit, hyperactivity or impulsivity. It should be noted that this pattern should be specified comparatively. That is, the degree of a child's attention deficit or hyperactivity should be investigated and analyzed according to a comparison with other children of the same age who have the identical growth conditions (Samadi, 2010).

Attention deficit/hyperactivity disorder can cause remarkable problems in children's educational, cognitive, social and emotional performances. Later in adulthood, it can have a negative impact on their family and job performances. Furthermore, it should be noted that ADHD disorder is a neurological syndrome which is characterized by features such as impulsivity, distractibility and hyperactivity. This disorder causes problems in a child's natural growth process. In case it is not treated, it will enhance child's proneness and susceptibility to psychological and social damages in adulthood (Shoushtari et al., 2011). Hyperactivity is observed in families which can be analyzed and interpreted in different ways. For instance, it can be assumed that the child with ADHD grows up with parents who also have this disorder. Hence, it enhances the interpretation that it might be mainly caused by the genetic factors. Research studies indicate that fathers having ADHD are more inefficient and unproductive than the healthy fathers (since their educational methods are ineffective and play the role of a conservative traditional parent). Parents' ineffectuality and inefficiency can aggravate their children's troublesome and annoying behaviors. Psycho-dynamic theories about ADHD underscore the probable role of improper and ineffective training and education of the children. Children with hyperactivity who demonstrate impulsivity have to be controlled by their parents in most cases. Under such conditions, parents' attention to the children's troublesome behavior plays a rewarding and reinforcing role. Hence, it can enhance the frequency and intensity of children's such behaviors (Ghanji \& Ghanji, 2014). Medical and psychological treatments independent of one another or in combination with each other have attracted the researchers' attention, and concurrent efforts and actions of parents, psychiatrists and psychologists have been used in this regard. Medicines which have had highly significant and dependable effect on treating ADHD include the followings: central nervous stimulants (CNS) are an important 
combinations of methylphenidate, dextro amphetamine and amphetamine which have immediate and long-term effects. Another type of methylphenidate, namely Focalin, has been recently released in the market which is intended to help increase the patient's ability to pay attention, stay focused on an activity, and control behavior problems. Indeed, it was used to minimize the undesirable effects of hyperactivity/attention deficit and maximize concentration (Sadouk, 2007). The most significant proven treatment of ADHD which can be used together with medical therapy is known as cognitive behavioral therapy. Inasmuch as the cognitive-behavioral therapy does not have the side effects which are the case with medical therapy, it can be more useful in some cases. In general, it can be argued that medicines merely cannot meet the treatment needs of the community of children with ADHD. Hence, medicines are considered to be only one facet of a multi-faceted diet and program. In fact, social skills groups, training parents of children with ADHD and behavioral interventions used at school and home have been mainly successful and effective in managing children with ADHD. Evaluating and treating learning disorders along with the additional psychiatric disorders is very important (Jannatian et al., 2008). Indeed, it should be noted playing is an indispensable aspect of child life. Playing and games have been integrated with children's lives in such an obvious way that it is taken for granted. That is, it is ignored since it is assumed that it is ubiquitously available in children's lives. Children are highly aware of each other's moods and behaviors and also are aware of their surrounding context. Hence, psychologists and child play experts are highly interested in investigating, analyzing and understanding the innovative reactions of children to plays and games. It is under these circumstances that detailed information can be obtained about children's relationships and non-verbal emotions by means of their movements and actions and their demands and interests become obvious. Play therapy is a method by which we can help children suffering from certain problems so that they can handle their problems. Sometimes, the intellectual ability and maturity of a child is less than that required in tools which are used for measuring and evaluating their cognitive capabilities. In a similar vein, due to severe distress, they might not be able to use their mental abilities to respond accurately to a test. Otherwise, because of the low age of children, we cannot give them a standard test. Under these conditions, evaluation can be made through plays which is considered to be an appropriate alternative. There are different models for play therapy each of which is flexible enough to applied for achieving the purpose. The purpose is to playing a game by the child and the therapist in order to solve the cases which are problematic for the child (Samadi, 2010).

One type of play therapy is referred to as animal-assisted play therapy. It is regarded as a novel technique and method which is recently used in the developed countries for treating disorders in children and even adults. Although the efficacy of play therapy for children with problems have been investigated and acknowledged in foreign countries, the animalassisted type of play therapy and its effects are an under-researched issue which have not been fully addressed (at least in the context of the present study (Iran)). Indeed, AAT (animalassisted therapy) is a therapy and rehabilitation method in which animals can facilitate the patient's behavior in many conditions. They can lead to positive changes in the patient's health and behavior. In fact, the communication feedback among the patient, animal and the therapist can significantly reduce the symptoms of a disease and improve his/her life quality (Dimitrijević, 2009). The children with ADHD suffering from the problem of attention deficit 
also cause some problems for their parents. Such children's conditions lead to the dissatisfaction of their parents with their lives and in poor life qualities. From the very beginning of their lives, children become familiar with domestic animals on TV and radio and see their images on clothes. Hence, a positive relationship between animals and children is gradually established. AAT can play an effective role in the process of treating children with functional and social disorders. It can be used as a catalyst in children's treatment process. The intended objectives in AAT are: $1 . \quad$ Improving children's communication skills, 2. Reducing behavioral problems, 3. Enhancing self-confidence and concentration, 4. Developing a peaceful and secure environment for a better interaction with children, 5. Reducing distress, anxiety, depression, etc. in children. Animal testing and evaluation for determining whether they can be effective and appropriate for children's therapy include the followings: sociability, child-friendliness and people-orientedness of animals, ease of touch, reliability and predictability and controllability (Jackson, 2012). It appears that the first recorded application and use of animals in a treatment environment was in York in England by William Tuke. He used a friendly association of farm animals such as rabbits, hens, chicks, etc. for treating patients and enhancing good feelings in them. He observed that using AAT can result in the reduction of medicine use in the patients. Later in the late 1960s, Levinson proposed a pioneering AAT for child therapy in which he took his own dog to the treatment sessions of the children. He believed that the presence of a domestic animal can enhance psychological security among children.

Adding and supplementing animals can have a remarkable impact on children's growth. Indeed, keeping domestic animals can lead to the development and improvement of social skills, respect, self-confidence and a sense of worthiness in children. In north America, one of the recorded initial applications of animals in the medical environment is related to the St. Elizabeth hospital in Washington, DC in 1919 which was reported by James Bossard. He contended that animals as a supplementary treatment are of high significance. Based on his case studies and personal experiences, Bossard argued that domestic animals play a remarkable role in producing unlimited and unconditional source of love, a companion for children. They can be used by children's teachers in training toilet use, training sexual issues and responsibility. Recently, Delta society, a non-profit organization in 1977, has been founded for enhancing useful mutual relationships between humans and animals and for improving people's health, independence and quality of life (Urichuk \& Anderson, 2003).

With respect to the above-mentioned problems of children with ADHD and the research gap in AAT, the present study was designed to investigate the impact of treatment interventions, (i.e., playing with domestic animal) on the parents of children with ADHD.

\section{Materials and Methods}

The study reported in this paper is a singletest experimental method which is highly common in behavioral sciences. In such studies, the focus is on controlling confounding variables. For the purpose of this study, two participants under age seven (one male and one female) were selected from among the intended population of children with ADHD through the screening methods. Furthermore, in addition to the qualitative analysis of the scenarios (plans) designed for each treatment session, statistical analysis of data illustrated in the produced figures, diagrams and charts (via Excel software) was conducted. Thus, the impact of the profile of independent variable (animal-assisted play therapy) on the dependent variable (parents' life quality) was 
investigated (Mohammadpour, 2013). Furthermore, the improvement rate and the effect size of the clinical effectiveness of the independent variable on the dependent variable were measured through the following equation:

$$
\mathrm{A} \%=\frac{\mathrm{A}_{0}-\mathrm{A}_{1}}{A_{1}}
$$

In this equation, $A \%$ denotes the improvement rate which should be greater than $50 \%$ so that it can be regarded as significant and meaningful. AO indicates the difference of the last score of the baseline and A1 indicates the last score of the intervention score (Sohrabi et al., 2012).

$$
\mathrm{d}=\frac{M_{1}-M_{2}}{S_{\text {poold }}}
$$

In this equation, $d$ stands for the effect size (i.e., the degree of the effectiveness of the treatment intervention). M1 denotes the average baseline of each individual and $M 2$ refers to the average treatment sessions of each individual divided by $\mathrm{S}$ which is the total standard deviation. This was computed by the SPSS. It should be noted that, in the single-test experimental method, only the visual analysis of the figures and diagrams can be used for examining and analyzing the impact of the independent variable on the dependent variable. That is, the trend for the effect of the independent variable on the dependent variable can be easily observed in the figure analysis. Moreover, the effect size statistic indicates the magnitude and degree of the efficacy of the independent variable with regard to the dependent variable. That is to say, in case the magnitude of the effect size is up to 0.41 , the effect size is interpreted to be weak; if it is between 0.42 and 1.15, it can be maintained that the effect size is about average. Nevertheless, based on the criterion specified by Cohen (1988), if the obtained value for the effect size is between 1.16 and 1.51, it is acceptable. Also, in case it is greater than 1.51, the effect size is at an optimal and desirable level.

\section{Procedure}

In this study, the Fifth Edition of Diagnostic and Statistical Manual (DSMV) was used as the criterion for selecting the participants. According to the specified research method, having selected the samples, the researchers spent three sessions for measuring the dependent variable by means of the SF-36 questionnaire (Yektakhah et al., 2014). Furthermore, the parents were informed about the purpose of the educational-medical intervention. In the baseline stage, known as stage (A), the dependent variable was measured without reference to the dependent variable so that the values obtained for the dependent variable in this initial stage can be compared with those of the next stage. In other words, the results of the baseline stage were supposed to be compared with those of the intervention stage so that the degree of the impact of the independent variable on the dependent variable can be determined. After the baseline stage, the treatment intervention was operationalized according to the specified plan and procedure. Indeed, the treatment interventions were carried out for 6 sessions and each session was done in 45 minutes. Throughout these interventions, the designed animal-assisted (rabbit) play therapy was implemented. After session 2, session 4 and session 6, the dependent variable was measured. On the whole, the dependent variable was measured three times in the interventions. The Final measurement of the dependent variable was done at the end of the operationalization of the intervention.

$\begin{array}{llll}\text { Participants } & \text { Age } & \text { Gender } & \text { Former } \\ \text { treatments Karina } & 7 & \text { Female Treated } \\ \text { with methylphenidate for } 3 \text { months Alireza } 6 \\ \text { years and } 8 \text { months } & \text { Male } & \text { Treated } & \text { with } \\ \text { methylphenidate for } 1 \text { year } & & \end{array}$




\begin{tabular}{llll}
\hline Participants & Age & Gender & Former treatments \\
\hline Karina & 7 & Female & Treated with methylphenidate for 3 months \\
Alireza & 6 years and 8 months & Male & Treated with methylphenidate for 1 year \\
\hline
\end{tabular}

Table 1: The demographic characteristics of the participants

As mentioned in Table 1, Karina, a 7-year old girl, was the only child of her family. Since she was five, she has been irregularly treated by medicine. The medicine (Ritalin) was cut for a period but it was given again. Alireza, a 6-year

was also the only child of his family who has been treated by Ritalin since he was 5 .

\section{Results}

SF-36 questionnaire: and 8-month boy was the other participant. He

\begin{tabular}{cccccccccc}
\hline Before & Physical & Mental & Treatment & Physical & Mental & After the & Physical & Mental \\
treatment & health & health & period & health & health & treatment & health & health \\
& subscale & subscale & & subscale & subscale & period & subscale & subscale \\
\hline 115 & 31 & 40 & 120 & 35 & 56 & 122 & 31 & 61 \\
100 & 33 & 45 & 118 & 35 & 56 & 109 & 31 & 61 \\
109 & 32 & 38 & 124 & 35 & 56 & 105 & 31 & 61 \\
\hline
\end{tabular}

Table 2: The scores of the SF-36 questionnaire for the first participant (Karina)

\begin{tabular}{cccccccccc}
\hline Before & Physical & Mental & Treatment & Physical & Mental & After the & Physical & Mental \\
treatment & health & health & period & health & health & treatment & health & health \\
& subscale & subscale & & subscale & subscale & period & subscale & subscale \\
\hline 110 & 32 & 40 & 109 & 30 & 46 & 115 & 29 & 44 \\
105 & 30 & 40 & 118 & 30 & 46 & 120 & 31 & 46 \\
100 & 28 & 45 & 122 & 30 & 46 & 118 & 30 & 45
\end{tabular}

Table 3: The scores of the SF-36 questionnaire for the second participant (Alireza) 
As it is shown in figure 1, three stages, namely before treatment, during treatment and after treatment, were considered in this study. Noticing the figure, we can observe that the parents' life quality had a falling trend before the treatment. During the treatment period, their life quality had a relatively rising trend. After the treatment, the life quality of Karina's parents decreased (indicated by the red curve). However, in the case of Alireza's parents, their life quality had a slight fall at first (indicate by the blue curve); nevertheless, after some time, it had a little rise. These reveal the effect of the treatment method on the parents' life quality, although the effect was not very strong.

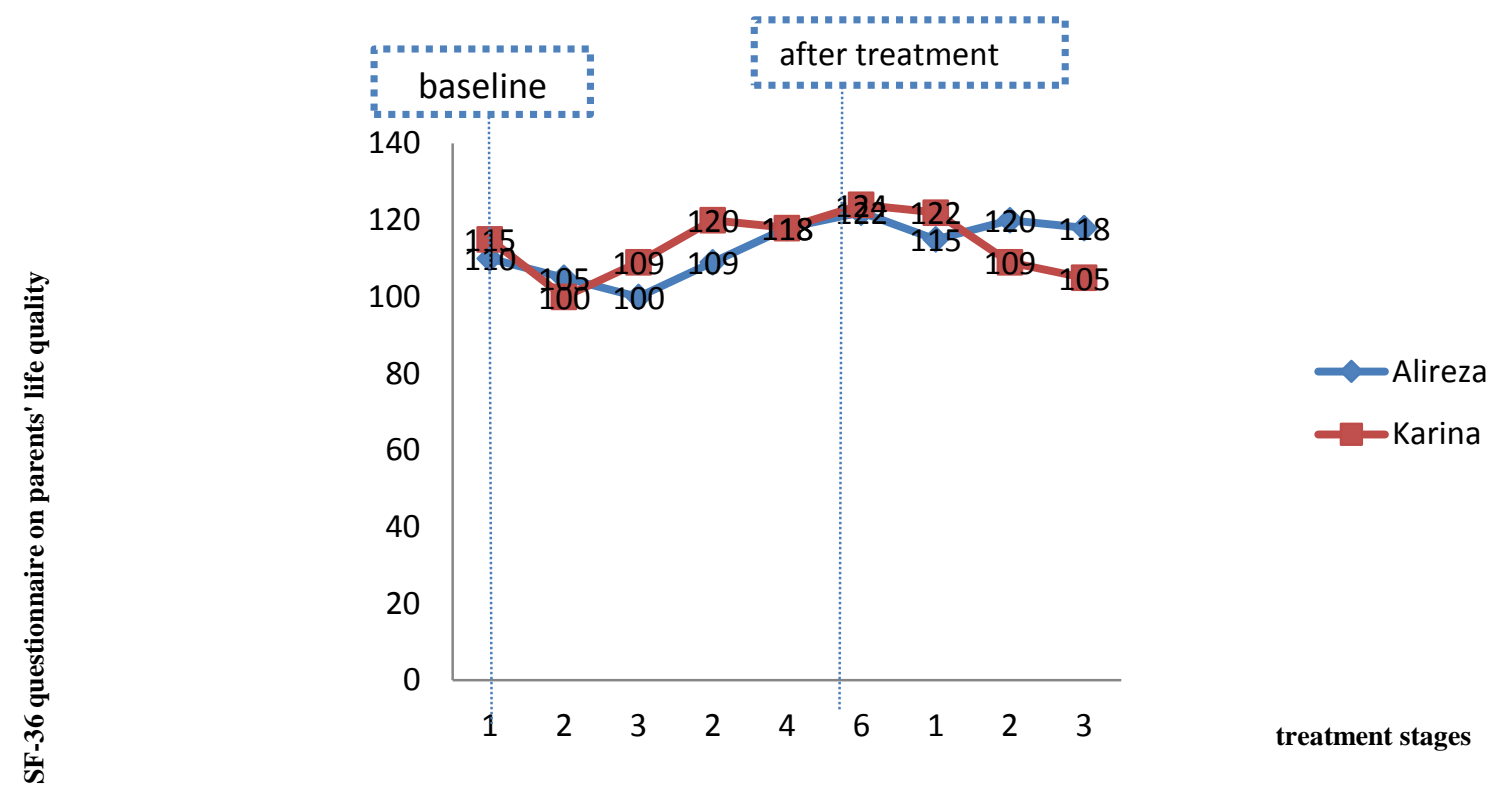

Figure 1: Life quality test of parents through SF-36 questionnaire

The physical and mental subscales depicted in figures above indicate that the parents' physical and mental health depend on the environmental situations and their daily conditions. AS shown in figure 2, the physical health of Alireza's parents had a descending trend at the beginning of the treatment. However, during the treatment, it increased slightly. Also, after the treatment, their physical health decreased and then increased marginally again. Regarding Karina's parents (indicated by red curve), their physical health had a rising and falling trend before the treatment. During the treatment period, their physical health increased but after the treatment, it decreased. Figure 3 illustrated the mental health of the parents. As shown in this figure, the mental health of both parents had a falling trend before the treatment but it had a rising trend during the treatment period. After the treatment, the parents' mental health was approximately fixed and non-varying. In general, based on the results which are depicted in these figures, it can be maintained that this treatment method (AAT) was effective on the parents' physical and mental health.

Measuring the rate of improvement 
Based on the conducted statistical obtained:

measurements, the following results were

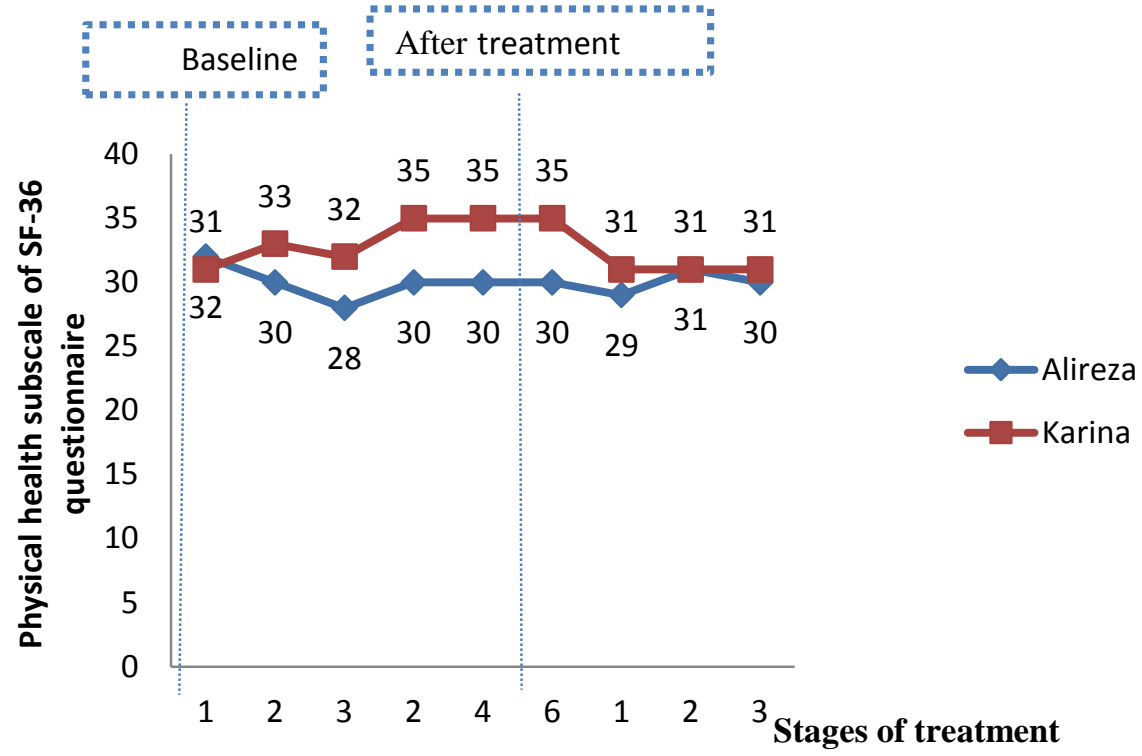

Figure 2: Physical subscale of the parents in the SF-36 life quality questionnaire

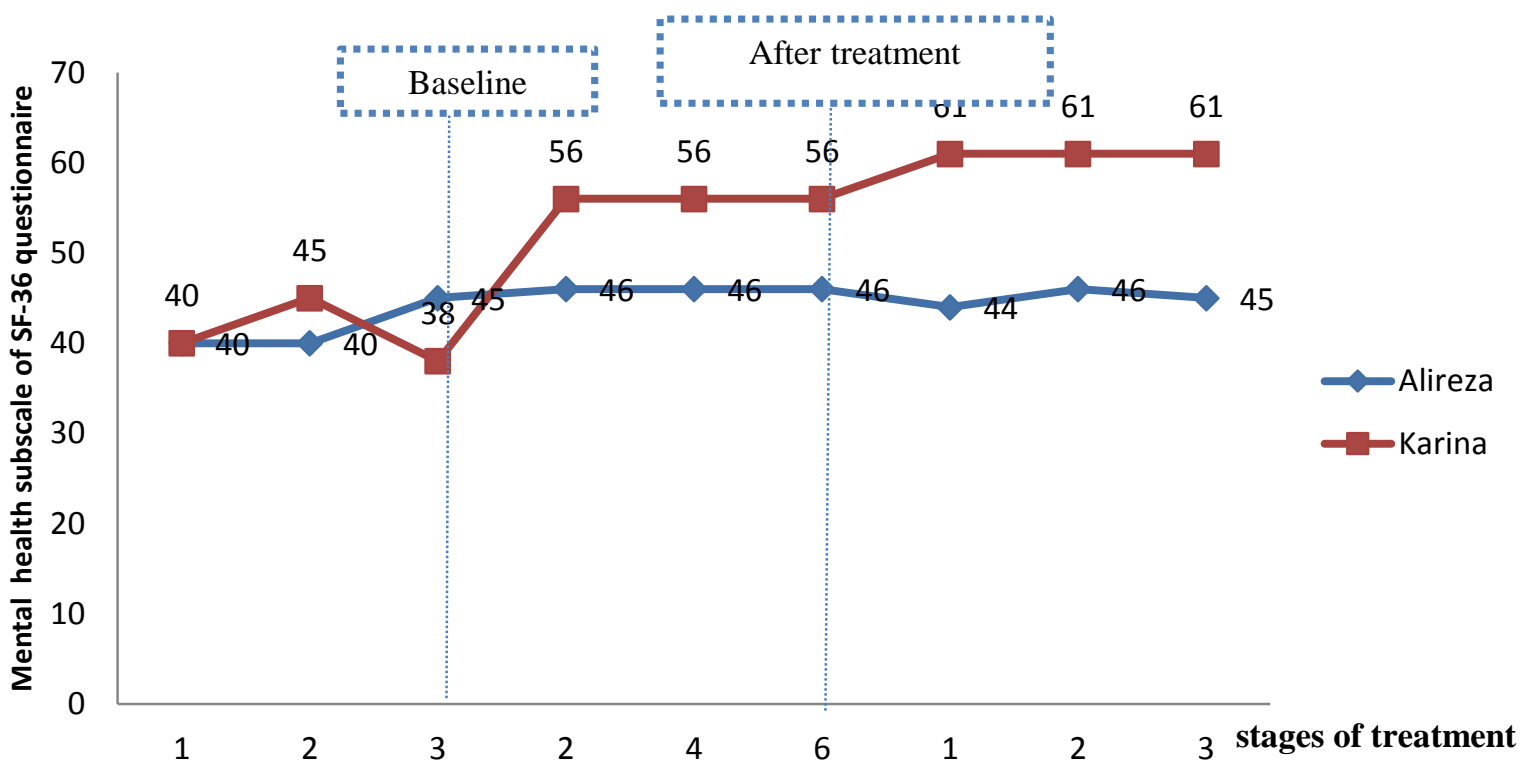

Figure 3: Mental health subscale of the parents in SF-36 life quality questionnaire 


\begin{tabular}{ccc}
\hline $\begin{array}{c}\text { Improvement } \\
\text { rate in the main } \\
\text { SF-36 test }\end{array}$ & $\begin{array}{c}\text { Physical health } \\
\text { subscale of the }\end{array}$ & $\begin{array}{c}\text { Mental health } \\
\text { subscale of the }\end{array}$ \\
\hline $0 / 12 \%<50 \%$ & $0 / 08 \%<50 \%$ & $0 / 32 \%<50 \%$ \\
\hline $\begin{array}{l}\text { Table 4: Improvement rate of the first } \\
\text { participant (Karina) }\end{array}$ & in SF-36 test \\
\hline Improvement rate & Physical health & Mental health \\
in the main SF-36 & subscale of the & subscale of the \\
test & parents in SF- & parents in SF-36
\end{tabular}

36

$0 / 18 \%<50 \% \quad 0 / 06 \%<50 \% \quad 0 / 02 \%<50 \%$

Table 5: Improvement rate of the second participant (Alireza) in SF-36 test

As shown in Tables 4 and 5, Karina's scores were significant in the first test which indicates the improvement rate. However, in the other test, neither Alireza nor Karina had clinical improvement rates. Hence, they were not significant.

Effect size in $\quad$ Effect size for $\quad$ Effect size for

the main SF- physical health of mental health of

36 test the parents in SF- the parents in SF-

$36 \quad 36$

1.45 (good) $\quad 1.70$ (optimal) 1.76 (optimal)

Table 6: Cohen's d effect size for the first participant (Karina) in SF-36

Measuring Cohen's d or the effect size As displayed in Tables 6 and 7, it can be argued that the dependent variable (AAT) was able to significantly improve the dependent variable clinically (improvements in symptoms and signs of ADHD and parents' life quality).
Effect size in
Effect size for
Effect size for
the main SF- physical health of mental health of
36 test
the parents in SF-
the parents in SF-

36

36

1.38 (good)

0 (no effect)

1.47 (good)

Table 7: Cohen's $d$ effect size for the second participant (Alireza) in SF-36 test

\section{Discussion and conclusion}

When compared with the similar research studies conducted outside the context of this study (Iran), it should be noted that there are research limitations for investigating and experimenting this treatment intervention (AAT) in the context of the present study (Iran). However, although the limitations were regarded as obstacles and difficulties for conducting this study, the results of this study revealed that animal-assisted play therapy can be regarded as a promising psychotherapy for different patients at different age groups who suffer from physical and mental problems. In modern medicine, there is an increasing emphasis on and preference for non-aggressive and non-pharmacological treatments for patients. Seniors, children, cancer patients and the disabled have had remarkable improvements under this type of treatment. For instance, in a research study conducted in a hospital in Tornio, Italy, 28 sick elderly people were divided into two groups (i.e., experimental and control groups). Within the experimental group, the participants met a domestic cat three sessions a week (one hour) which continued for six weeks. The results indicated that this group had a significant difference from the control group. It was found that the patients treated with a domestic animal (cat) had remarkable improvements in terms of depression signs and symptoms. Also, their blood pressures decreased significantly 
(Stasi et al., 2004). Another study was conducted on 500 children between ages 3 to 17 in the U.S. from November 2005 to December 2008 in which domestic animals were used to reduce children's pains. They found that there was a significant reduction of pain in the treatment group which was not the case with the control group. In this study, one person was the patient, there was one domestic animal and one more person was the facilitator. The purpose of the study was to improve the physical, social, emotional and cognitive conditions of the children. A number of trained animals such as birds, Hindi pigs, fish, horse, Dolphin and some other animals were used based on the patients' needs and tastes. The results revealed that the children being accompanied with a domestic animal for 15 minutes demonstrated a condition which was similar to consuming oral Acetaminophen (Braun et al., 2009). In one more study which was designed to improve the life quality of cancer patients in Carrara City Hospital in Italy, 89 (male and female) patients were selected and included in an experimental group. They were treated with a domestic animal (dog) for 25 weeks. They found that the depression and arterial blood supply of this group had been significantly improved (Orlandi et al., 2007). However, it should be noted that AAT might be implemented differently with respect to different situations and conditions. The majority of the studies conducted on AAT indicated that children and even adults with different behavioral and emotional problems who went through AAT had enhanced their social skills, self-efficacy, self-esteem and emotional and cognitive conditions. They were also able to reduce anxiety and depression. Furthermore, it helped the patients establish and maintain good relationships among their peers and improve their self-efficacy. However, it should be noted that, with regard to research limitations in this domain of study, further studies should be conducted (Adams, 2009).
The studies carried out on the association between humans and animals indicate that stroking an animal can have many physiological and psychological merits. It has a relaxing effect for the individuals who are in stressful situations such the time just before a surgical operation (Velde et al., 2005). Moreover, being accompanied with an animal can facilitate learning and a sense of security. In the present study, a model was proposed which demonstrated the association between humans, animals and social environments. Furthermore, this study substantiated that animals can be helpfully utilized as a treatment and therapy in different areas. In a study, two boys (aged11 and 12) suffering from emotional disorders such as damaging appliances, aggression and distraction were observed for 12 weeks and their families were interviewed. The results of the observation indicated that using AAT can help improve their conditions. As a result of AAT, they had more improvements than the other peers who did not receive AAT (Kogan et al., 1999). Another interesting finding in these studies is the enhancement of the life quality of the children's parents. Also, AAT can be used as a complementary treatment along with medication and pharmacological treatments. Indeed, it can be maintained that if children with ADHD play with animals under the mentioned conditions and, besides that, play with their peers, hence, their concentration, learning, sense of responsibility and emotional status will be improved and optimized. As a result, their parents can easily interact with them. Consequently, the degree of parents' satisfaction, improvement rate and the effect size will be remarkably enhanced.

As children care for the domestic animals, degree of impulsivity of children decreases and their sense of love and affection increases. Equally, their parents' impulsivity also decreases. However, it should be noted that as animal-assisted therapy is executed with less 
limitations, its potential effectiveness can be better observed. Otherwise, it might not fulfill the expected outcomes. That is, as shown in the tables above, AAT did not have a remarkable impact on the physical health of the second participant (Alireza).

\section{References}

1. Adams, N. (2009). Animal assisted interventions for adolescents with emotional and behavioural problems. A rewiev of selected literature. School of psychology, Psychiatry and psychological medicine. Monash university. [Verkkojulkaisu]. [Viitattu 3.4. 212]. Saatavana: http://www. Itw. com. au/docs/Naomi\% 20Adams\% 20AAT\% 20Lit\% 20Review. pdf.

2. Angulo, F.J., Siegel, J.M., \& Detels, R. (1996). Pet ownership and the reliability of the companion animal bonding scale among participants of the multicentre aids cohort study. Anthrozoös, 9, 5-9.

3. Barba, B.E. (1995). The positive influence of animals: animal-assisted therapy in acute care. Clinical Nurse Specialist, 9, 199-202.

4. Braun, C., Stangler, T., Narveson, J., \& Pettingell, S. (2009). Animal-assisted therapy as a pain relief intervention for children. Complementary Therapies in Clinical Practice, 15(2), 105-109.

5. Cohen, J. (1988). Statistical power analysis for the behavioral sciences (2nd ed.). Hillsdale, NJ: Lawrence Earlbaum Associates

6. Dimitrijević, I. (2009). ANIMAL-ASSISTED THERAPY-A NEW TREND IN THE TREATMENT OF CHILDREN AND ADDULTS. Psychiatria Danubina, 21(2), 236-241

7. DSM5, (2014). Psychological Pathology DSM5. Ganji, M., \& Ganji, H. Tehran: Savalan Publications.

8. interactions of older adults with dementia. American Journal of Alzheimer's Disease and

9. Jackson, J. (2012). Animal-assisted therapy: the human-animal bond in relation to human health and wellness. Capstone paper, Winona State University

10. Janatian, S., \& Nouri, A., \& Shafti, E., \& Molavi, H., \& Samavatian, H. (2008). The Effectiveness of CognitiveBehavioral Oriented Play Therapy on 9-11-year old Male Students' Symptoms of ADHD. Research on Behavioral Science, 6(2).

11. Kogan, L. R., Granger, B. P., Fitchett, J. A., Helmer, K. A., \& Young, K. J. (1999, April). The human-animal team approach for children with emotional disorders: Two case studies. In Child and Youth Care Forum (Vol. 28, No. 2, pp. 105-121). Kluwer Academic Publishers-Plenum Publishers

12. Mohammadpour, V., \& Babapour, J., \& Bakhshipour, E. (2013). The Impacts of Video Modelling on Enhancing SelfEfficacy Skills of Children's with Autism. Journal of Medical Science, 20 (106).

13. Orlandi, M., Trangeled, K., Mambrini, A., Tagliani, M., Ferrarini, A., Zanetti, L., ... \& Cantore, M. (2007). Pet therapy effects on oncological day hospital patients undergoing chemotherapy treatment. Anticancer research, 27(6C), 4301-4303.

14. Other Dementias, 18(6), 353-358.

15. Pet Partners. (n.d.). Retrieved from www.deltasociety.org.

16. Pichot, T., \& Coulter, M. (2006). Animal-assisted brief therapy. New York, NY: Routledge.

17. Richeson, N. (2003). Effects of animal-assisted therapy on agitated behaviors and social 
18. Sadouk, B., Sadouk, V. (2007). A synopsis of the clinical Psychiatric-Behavioral Sciences by Pourafkari, N. (2003). 3rd Edition. Tehran: Shahrab Publications.

19. Samadi, S. A. (2010). Play Therapy, Research Theories and Intervention Methods. 1st Edition. Tehran: Danzheh Publications.

20. Serpell, J. A., Coppinger, R., Fine, A.H., \& Peralta, J.M. (2010). Welfare considerations in

21. Sohrabi, F., \& Jafarifard, S., \& Zarei, S. \& Eskandari, H. (2012). Efficacy of Awareness-based Cognitive Therapy on Panic Disorders: a case study. Journal of Clinical Psychology, 4(4).

22. Spielberger, C.D., Gorssuch, R.L., Lushene, P.R., Vagg, P.R., \& Jacobs, G.A (1983). Manual for the State-Trait Anxiety Inventory. Consulting Psychologists Press, Inc

23. Stasi, M. F., Amati, D., Costa, C., Resta, D., Senepa, G., Scarafioiti, C., ... \& Molaschi, M. (2004). Pet-therapy: a trial for institutionalized frail elderly patients. Archives of Gerontology and Geriatrics, 38, 407-412.

24. therapy (pp. 480-502). San Diego, CA: Academic Press.

25. therapy and assistance animals. In A. H. Fine (Ed.). Handbook on animal-assisted

26. Urichuk, L. J., \& Anderson, D. L. (2003). Improving mental health through animal-assisted therapy. Chimo Project

27. Velde, B. P., Cipriani, J., \& Fisher, G. (2005). Resident and therapist views of animal-assisted therapy: Implications for occupational therapy practice. Australian Occupational Therapy Journal, 52(1), 43-50.

28. Yektakhah, S., \& Alameh, M., \& Gorji, R. (2014). Investigating the General Health and Life Quality of of Mothers Having Children with Autism. Education and Training for the Exceptional, 1(123). 